This item was submitted to Loughborough's Research Repository by the author.

Items in Figshare are protected by copyright, with all rights reserved, unless otherwise indicated.

\title{
HADRIAN: A human factors computer-aided inclusive design tool for transport planning
}

\section{PLEASE CITE THE PUBLISHED VERSION}

http://dx.doi.org/10.1049/ic:20060184

\section{PUBLISHER}

(C) Loughborough University. Published by The Institution of Engineering and Technology

\section{VERSION}

AM (Accepted Manuscript)

\section{PUBLISHER STATEMENT}

This work is made available according to the conditions of the Creative Commons Attribution-NonCommercialNoDerivatives 4.0 International (CC BY-NC-ND 4.0) licence. Full details of this licence are available at: https://creativecommons.org/licenses/by-nc-nd/4.0/

\section{LICENCE}

CC BY-NC-ND 4.0

\section{REPOSITORY RECORD}

Porter, J. Mark, Russell Marshall, Keith Case, Diane E. Gyi, Ruth Sims, and Steve Summerskill. 2019. "HADRIAN: A Human Factors Computer-aided Inclusive Design Tool for Transport Planning". figshare. https://hdl.handle.net/2134/22271. 


\title{
HADRIAN: A Human Factors Computer-Aided Inclusive Design Tool for Transport Planning
}

\author{
$\mathrm{J} \mathrm{Mark} \mathrm{Porter}^{\mathrm{a}}$, Russ Marshall ${ }^{\mathrm{a}}$, Keith Case ${ }^{\mathrm{b}}$, Diane Gyi $^{\mathrm{c}}$, \\ Ruth Sims ${ }^{a}$ and Steve Summerskill ${ }^{a}$ \\ ${ }^{a}$ Department of Design \& Technology, Loughborough University, Leics LE11 3TU, UK \\ ${ }^{\mathrm{b}}$ Manufacturing \& Mechanical Engineering, Loughborough University \\ ${ }^{\mathrm{c}}$ Department of Human Sciences, Loughborough University
}

\section{Overview}

HADRIAN is a computer-based inclusive design tool developed initially to support the design of kitchen and shopping based tasks. The tool is currently being expanded to include data on an individual's ability to undertake a variety of transport-related tasks, such as vehicle ingress/egress, coping with uneven surfaces, steps, street furniture and complex pedestrian environments. A feature of the enhanced HADRIAN tool will be a journey planner that compares an individual's physical, cognitive and emotional abilities with the demands that will placed upon that individual depending on the mode(s) of transport available and the route options.

\section{Introduction}

There are ethical, legislative and financial reasons why products and services should be designed, wherever appropriate and possible, for the widest range of consumer ages, shapes, sizes, needs, preferences, abilities and aspirations. For example, it is estimated by the World Health Organisation that the world population of people aged $60+$ years will increase from 600 million in 2000 to 1.2 billion by 2025, and 2 billion by 2050 (WHO, 2006, http://www.who.int/ageing/en/ ). The WHO website also states that in 2006 about two thirds of all older people are living in the developing world; by 2025 it will be $75 \%$. Furthermore, it notes that the very old (age 80+ years) is the fastest growing population group in the developed world. The UK Design Council website (http://www.designcouncil.org.uk) states that $50 \%$ of Britain's adult (16+) population will be aged 50 or over in 2020 . It also points out that whilst 8.7 million people come under the remit of the Disability Discrimination Act 1995, fewer than five per cent are wheelchair users. Collectively they have an estimated disposable income of $£ 45-50$ billion. This increasingly older population, together with the disabled population, will affect market forces and impact upon the way that designers consider their end-users (Vanderheiden \& Tobias, 2000). Whilst young and able people are often considered to be able to 'adapt' to a poor design, there is typically an associated human cost. For example, a poor posture that has to be maintained for prolonged periods will result in a high incidence of musculoskeletal troubles and possibly sickness absence. People who are older or disabled have less opportunity to adapt to a poor design. In many cases, they are effectively 'designed out' and cannot use the product or service. The 'design for all' or inclusive design philosophy aims to reduce, if not eliminate, such problems. 
Inclusive design is an approach to design that seeks to ensure that mainstream products, services and environments are accessible to the largest number of people. We are currently witnessing a shift from designers and planners treating disabled and older people as separate cases, requiring special design solutions, towards integrating them into the mainstream through a more inclusive approach to the design of buildings, public spaces, products and services. Central to this inclusive approach is the challenge of understanding and quantifying the numbers of people adversely affected by decisions made during the specification and design process. This challenge has led to the creation and development of HADRIAN.

HADRIAN (Human Anthropometric Data Requirements Investigation \& ANalysis) is our computer-based inclusive design tool that was created through the UK EPSRC 'EQUAL' (Extending Quality of Life) initiative. The tool is now being further developed through the EPSRC Sustainable Urban Environment (SUE) Programme. Accessibility and User Needs in Transport for Sustainable Urban Environments (AUNT-SUE) is a multi-disciplinary consortium of researchers from London Metropolitan University, Loughborough University, University College London, RNIB, London Borough of Camden and Hertfordshire County Council. The aim of the consortium is to improve our understanding of the needs, abilities and preferences of people who experience transport-related exclusion in towns and cities. Better empathy with disadvantaged users and would-be users will be encouraged through an AUNT-SUE 'toolkit' to support planners, designers, operators, user groups and others working to make urban transport and street design more inclusive.

HADRIAN builds upon our 30 years plus experience in developing the SAMMIE system and providing support to a large number of industrial, commercial and government projects through SAMMIE CAD Ltd., a UK Ergonomics Society Registered Design Consultancy (see Porter et al 1999). Figure 1 shows our current SAMMIE human modeling tool that runs on Windows XP. As 'expert' users, we have also successfully used SAMMIE in a variety of inclusive design projects including the Brussels Tram 2000 project (see Figure 2). However, we feel there is a strong need to empower 'non-experts' so that inclusive design becomes a fundamental part of design practice.

HADRIAN was therefore created to make a step-function change in the way that anthropometric data are used in the design and evaluation of products and services. Our approach has been to replace numerous separate tables of population percentiles (e.g. for arm reach, hip breadth, sitting height and so on) with a holistic database of 100 individuals covering a wide range of shapes, sizes and abilities (see Figure 3). This approach adds significantly to the 'richness' of the data that a designer has access to. Additionally, by presenting the data as individual people the designer has a much greater empathy with those they are designing for. To assist in making use of the data there is a simple task analysis/synthesis tool that allows the designer to simulate various tasks with these individuals interacting with SAMMIE CAD models of equipment and products in the virtual environment. Each task element (e.g. reach to a device, look at instructions) is automatically analysed to identify if any of the individuals have a problem. If specific individuals experience problems, the designer can view these individuals' 'best attempts' to more fully understand the nature of the physical problems with a view to iteratively improving the design and making it more inclusive. Details of our methodology can be found in Porter et al (2003, 2004a, 2004b, 2005), Gyi et al (2004) and Marshall et al (2005). 
Although there are a number of inclusive design tools/methods available, none of these include consideration for the emotional issues of users' lives in an explicit manner. We are now adding to HADRIAN's functionality by including additional data concerning an individual's emotional and cognitive dimensions.

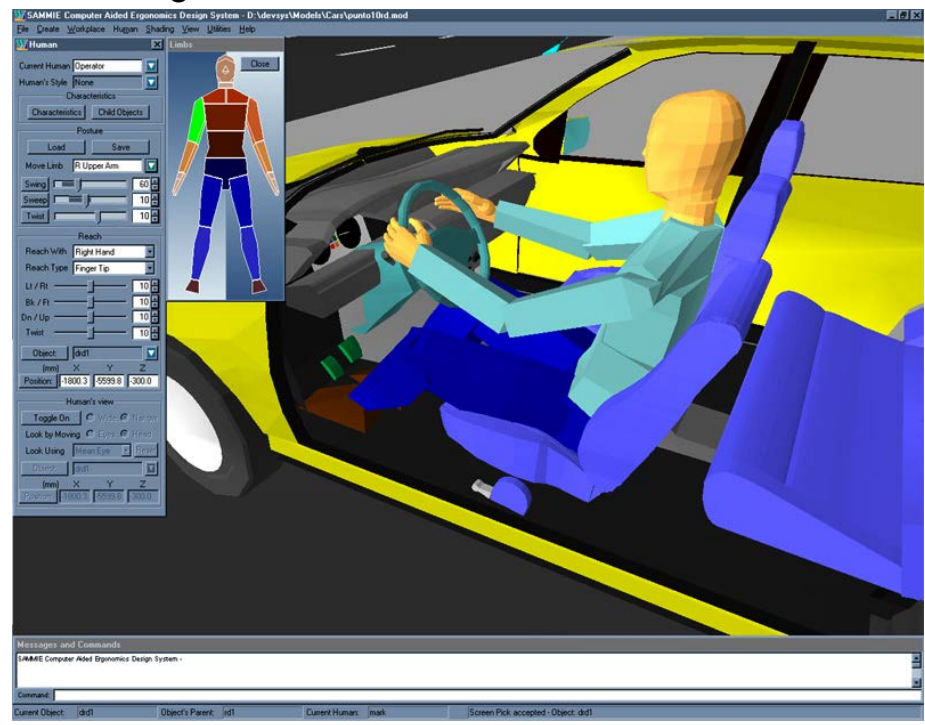

Figure 1: Latest version of SAMMIE runs on Windows XP (see http://www.sammiecad.com for further details of this human modeling system).
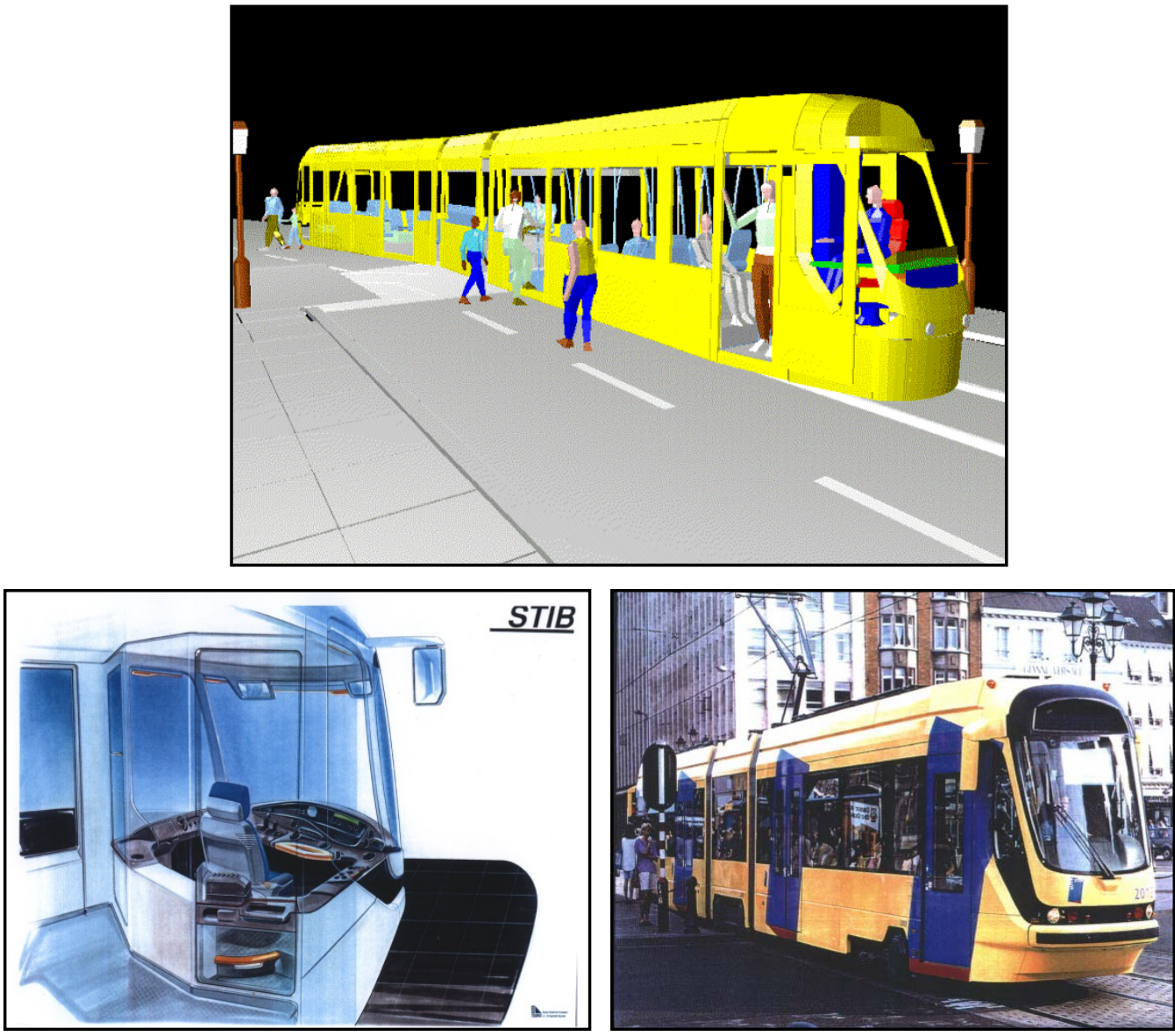

Figure 2: SAMMIE has been used in several multinational design projects working closely with designers from the concept stage onwards. 


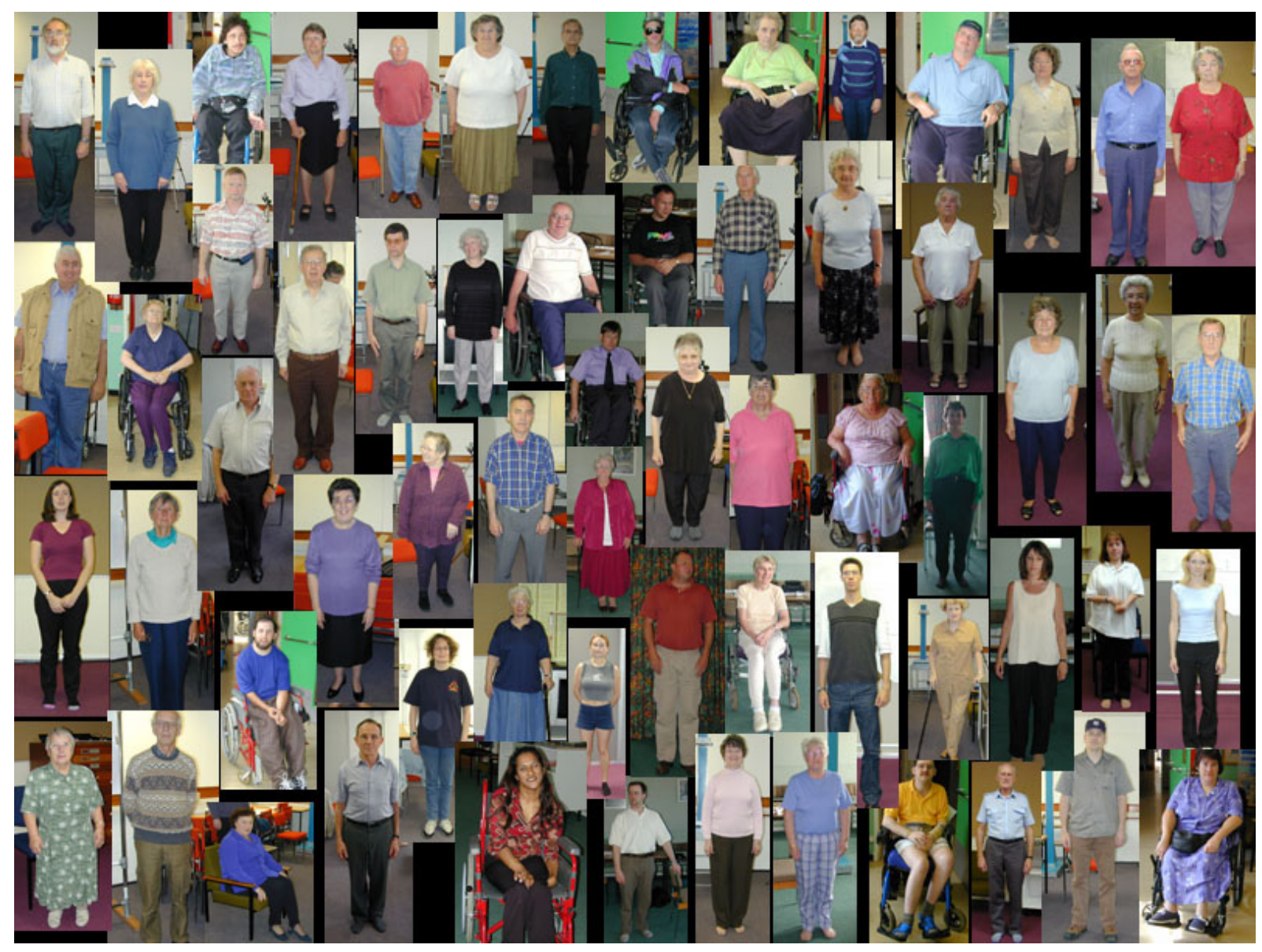

Figure 3: HADRIAN's database of 100 individuals covering a wide range of sizes and abilities. Each individual's data can be used as a design resource and to generate a digital human model of each individual using SAMMIE.

\section{Problems with percentiles}

'Design for all' or inclusive design needs to move from being a philosophical viewpoint to being a central feature of design practice. Key to this is establishing empathy between designers, who usually start their careers whilst young, healthy and able, and the people who would primarily benefit who are often older, in poor health and unable to achieve all the tasks they would like to with ease and confidence. Current design practice frequently involves using anthropometric and biomechanical databases that present percentile values for body size and strength, joint ranges for mobility and so on. These numbers do not motivate the designer to vigorously explore design solutions that are more inclusive. In fact, the commonly accepted view for mainstream design is to cater for only the $5^{\text {th }}$ to $95^{\text {th }}$ percentile users of a product or service. This is designing for numbers, not people. Today, we believe that it is no longer acceptable to continue this approach of deliberate 'designing out' of people who are in the top or bottom $5 \%$ of size or ability.

Percentiles are univariate in that they relate to only one dimension or variable. Knowing someone's stature does not provide you with an accurate estimation of their hip breadth, 
shoulder mobility or grip strength because these variables are poorly correlated.

Furthermore, people can be excluded from using a product or service because of a wide range of factors including their personal emotional and cognitive dimensions. For example, a person may be able to reach a control but not able to manipulate it as required; able to lift an item but not have the balance to carry it safely; able to see a timetable but not able to plan a journey route; able to walk 100 metres but not confident enough to cross a busy road; able to climb stairs but not willing to walk past a group of teenagers in an environment dominated by graffiti; and so on.

There is an important distinction between the specification of percentile values to be used for a particular design dimension and the percentage of the user population that will be accommodated in all respects. A common mistake made by many designers is to use the 5th percentile female stature and 95th percentile male stature manikins to assess a workstation, assuming that if both of these manikins can be accommodated then so can 95\% of the adult population. This is an incorrect assumption as it implies that those people 'designed out' because either their sitting height, hip breadth or leg length, for example, are greater than 95th percentile male values are all the same people. Similarly, all those with sitting eye height, arm length or leg length smaller than 5th percentile female values are assumed to be the same individuals. As these dimensions are not strongly correlated then these assumptions are incorrect. A study of air crew selection standards and design criteria analysis reported by Roebuck, Kroemer and Thomson (1975, page 268) illustrates the problem perfectly as it was shown that nearly half of the air crew were 'designed out' when the 5th to 95th percentile range was used on a large number of body dimensions (in this case 15 dimensions). Even limiting the number of dimensions to just 7 (sitting height, eye heightsitting, shoulder height-sitting, elbow rest height, knee height, forearm-hand length and buttock-leg length) 'designed out' over 30 percent of the available air crew.

Clearly, the univariate nature of anthropometric percentiles is a significant limitation to their success when being used by non-experts in the design process. Designers need to be able to consider multivariate issues right from the beginning of a design project; however, this is rarely achieved in practice until the project reaches the user trial stage using a full-size working prototype. By this stage it is often difficult to make substantial changes to the product. The next section describes how the HADRIAN inclusive design tool deals with multivariate issues and supports the designer during the early stages of the design process.

\section{Our approach to inclusive design}

The HADRIAN inclusive design tool includes several features that are briefly described below.

\section{a) Database of individuals}

Detailed information is provided on the size, shape, abilities, preferences and concerns of a wide range of people, each presented as individual datasets. Data are collected using traditional anthropometers and a body scanner (see Figure 4 for examples of the output) whilst a variety of experimental rigs have been developed to assess 3D reach volumes, kitchen and shopping tasks, and vehicle ingress/egress (see Figure 5). Furthermore, a transport activities questionnaire is used to obtain extensive information about the nature of 
any problems experienced when making a journey, for example: physical barriers of all types, cognitive issues with information presentation or wayfinding, or emotional concerns with poor lighting, badly maintained or overcrowded/deserted environments, and so on.

This range of information is presented to the designer as a set of screen displays for each person, including video clips showing them undertaking a variety of tasks such as lifting a baking tray with oven gloves on, reaching to food stuffs on a low or high shelf, entering and leaving a bus/coach/tram/train (see Figure 6). These data are both informative and foster empathy between the designer and these future users/consumers. Basic emotional and cognitive data related to 'activities of daily living', such as shopping, cooking and making a journey, are also presented. These screen displays are a very useful design resource and we have tried to make them easily navigable and to clearly show the extent of human variability that needs to be considered when practicing inclusive design. The anthropometric data taken from the body scans are used to create virtual SAMMIE human models for each individual in the database (see Figure 7), and these are used in the multivariate assessments described below.

\section{b) Task analysis/synthesis tool}

A simple task analysis/synthesis tool is provided whereby the designer can specify a series of task elements (such as look at, reach to, lift to, walk to, climb up) with reference to physical items in a CAD model of an existing product or a early prototype of a new design. The designer can specify parameters as appropriate (e.g. use thump tip reach for inserting a card into a card reader; specifying a viewing distance for specific character sizes), although the tool will set default settings for each individual otherwise (e.g. preferred hand). The series of task elements can be easily constructed to define the critical aspects of interacting with a product or service. For example, when using an ATM (cash dispenser) the series would include: 'look at screen', 'look at card slot', 'reach to card slot', 'reach to screen buttons', 'look at keypad', 'reach to keypad', 'look at cash tray', and 'reach to cash tray'.

\section{c) Multivariate assessment of each individual's ability to complete a task}

An automated analysis is then undertaken whereby each individual in the database is assessed in terms of their ability to complete successfully each task element. This procedure deals with the multivariate nature of interactions with products, integrating the relevant physical, emotional and cognitive issues. The physical issues are evaluated using the SAMMIE human models for each individual in the HADRIAN database to create a virtual simulation of the tasks, whilst the emotional and cognitive issues are assessed using personal look-up tables. The analysis presents the percentage of individuals within the database who are 'designed out' from using a product or excluded from using a service, and the designer is encouraged to seek further details by scrolling through virtual simulations of the problem(s) encountered by each person. This visualisation of the person and the problem encourages the designer to explore potential solutions by modifying the CAD model and repeating the analysis. 


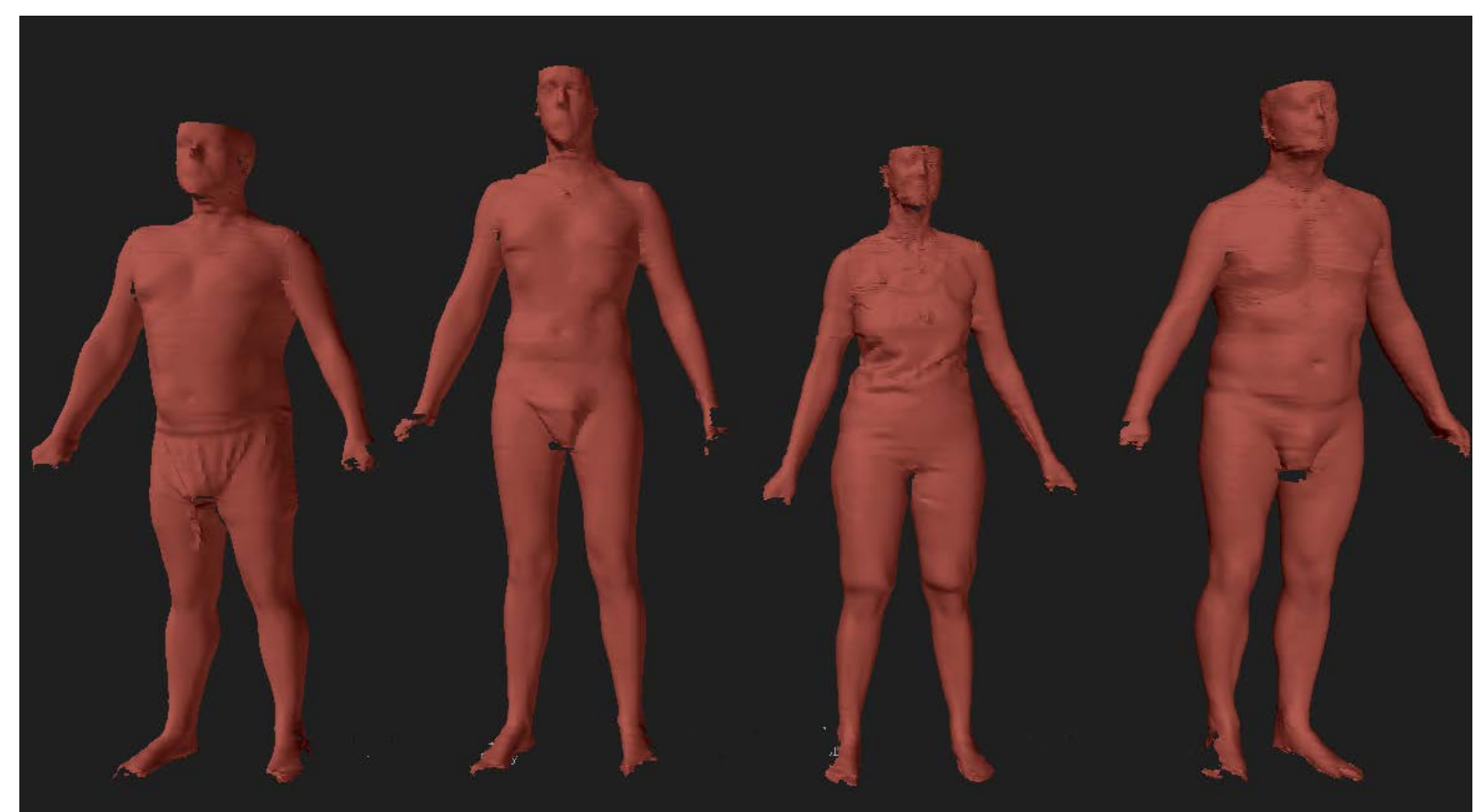

Figure 4: Scanned images for individuals that are used to collect anthropometric data and to construct the individual SAMMIE human models.

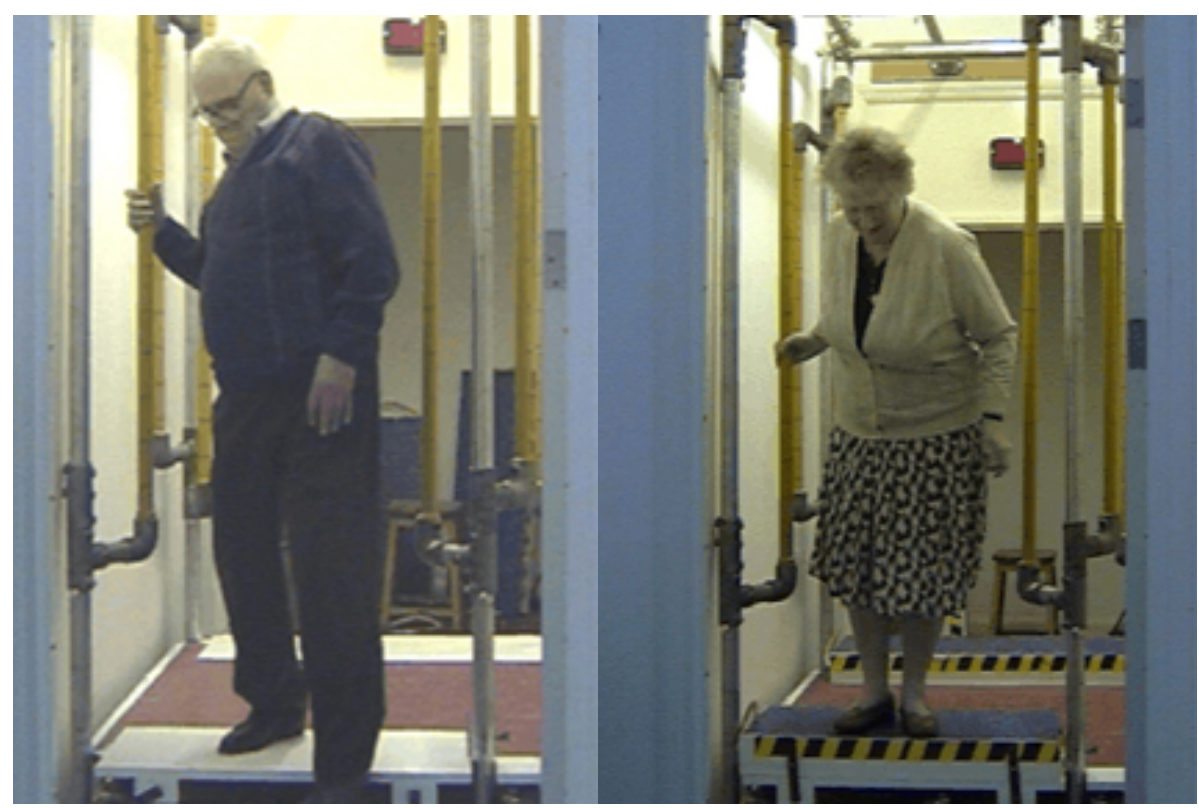

Figure 5: Extracts from video clips for two individuals leaving the vehicle ingress/egress rig. 


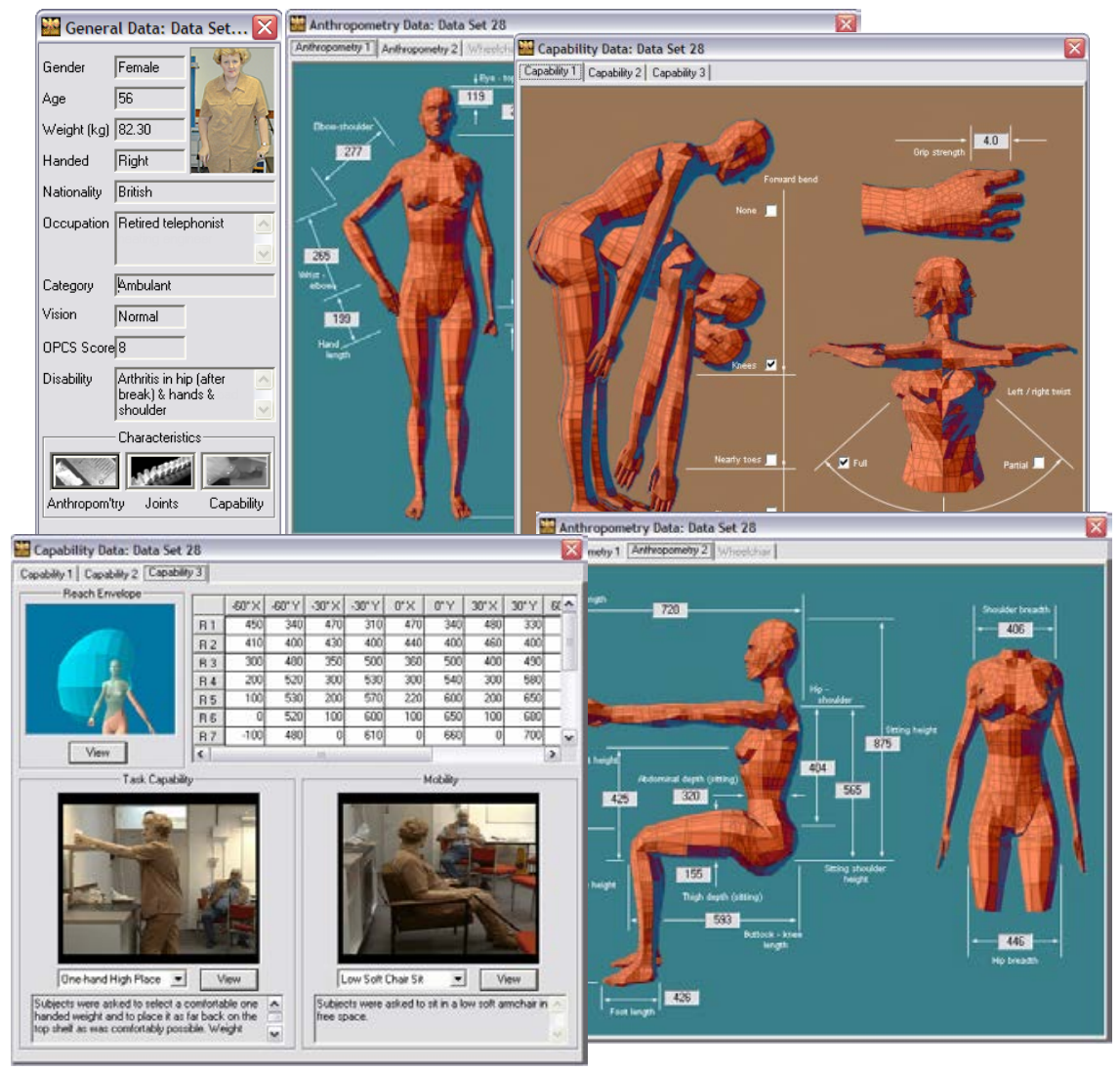

Figure 6: An example of screen displays for a particular individual within the HADRIAN database.

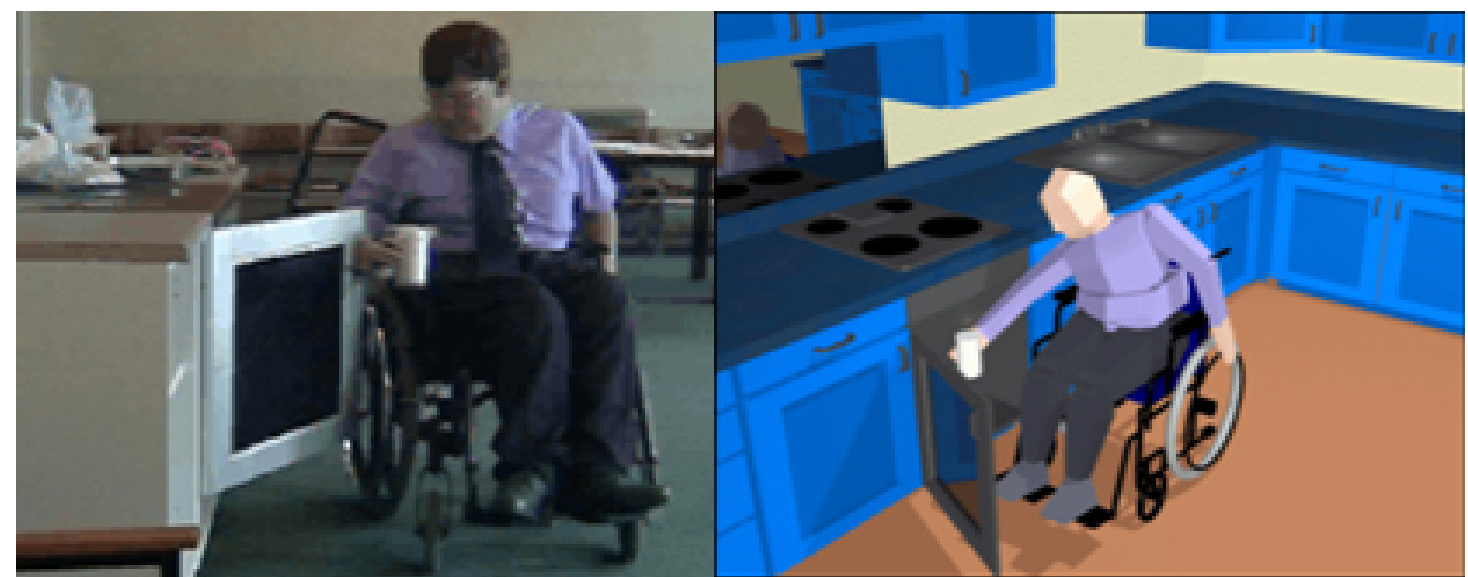

Figure 7: SAMMIE human models are constructed for each individual in the HADRIAN database.

HADRIAN does not present people as anonymous numbers in percentile tables (where individuals are lost forever). Instead, individual datasets are presented describing each person in terms of their body shape and size, abilities, coping behaviours and emotional characteristics. The designer is, thereby, both more knowledgeable about individual differences and more motivated 'to make a difference' due to the greater empathy with their problems in interacting with products and services. The interactive nature of the tool allows the designer to view video clips and other personal data for all individuals who are predicted to be 'designed out' from using a product or excluded from using a service. The nature of 
their predicted problems, be they physical, emotional or cognitive, or a combination thereof, are highlighted for each specific task element. Some people may not be able to climb on board a bus without help, others may be able to get on board but not have the confidence to get to their seat before the bus moves off, and some may be discouraged from using the bus as they know it is 'too' crowded or that the bus stop is in a dark and unpleasant location. In all such cases, people may decide not to use buses at all. The optimum solution to such problems involves both design (e.g. of the bus, bus stop/shelter etc.) and operation (e.g. driver training, scheduling of bus service etc.).

\section{Data collection issues}

Several issues have emerged during this research, some of which are discussed below.

\section{Participant selection}

The complexity of carer interactions was considered too difficult to quantify and model within the current software tool. Consequently, the decision was made to exclude those who are not physically able to get themselves out of their house and onto the pavement to join the transport system. Clearly, such people still have needs and aspirations for transport usage, and a future study could exclusively explore the considerations involved with individuals and carers.

It was our intention to revisit as many of the 100 people who had previously participated in the original EQUAL funded project concerning kitchen and shopping tasks to see if they would be willing to participate again in the AUNT-SUE transport-related project. We hoped this would enable some study of the longitudinal aspects of age and disability, due to the number of years since the first study data collection took place. However, several of the original participants have sadly died in the interim and some others are no longer able to get outside without assistance. Furthermore, we have experienced problems contacting many of the remaining participants as their contact details are now out-of-date. As a consequence, we have had to find many new participants for the AUNT-SUE project.

All participants were required to complete a medical screening questionnaire before the trials. Typically, medical screening questionnaires are used to exclude just the type of participants that our research is looking for. It was important that we were well informed of the potential consequences of a participant's current medical condition so that appropriate changes could be taken to reduce any identified risk during the data collection trials. For example, those participants with vertigo/dizziness were not asked to bend low down and those who were epileptic were not body scanned.

\section{Vehicle ingress and egress}

When making a journey using a public transport vehicle, people encounter a variety of step heights and handle locations during ingress and egress. We designed a rig to assess participants' abilities in these situations, and decisions concerning which heights and handle positions to study were made after referencing the relevant public transport regulations and making field observations within the Midlands area of the UK. Train carriages and trams in the UK are covered by the Rail Vehicle Accessibility (Amendment) Regulations (2000). This 
states the maximum step height should be $200 \mathrm{~mm}$ with handrails placed internally, on either side of the external doorways, between $700 \mathrm{~mm}$ and $1200 \mathrm{~mm}$ above the floor. From our observations it was found that step heights into trains varied between $180 \mathrm{~mm}$ and $280 \mathrm{~mm}$, with the one example of trams having no step at all. London Underground state that the maximum step height on their lines is $240 \mathrm{~mm}$. Buses and coaches (carrying more than 22 people for public usage) are covered by the Public Service Vehicle Accessibility Regulations (2000). This states that the maximum step height from pavement to bus should be $250 \mathrm{~mm}$, with the first handrail inside the bus being within $100 \mathrm{~mm}$ of the entrance and between $800 \mathrm{~mm}$ and $1100 \mathrm{~mm}$ above ground level. Observed step heights for buses were found to vary between $170 \mathrm{~mm}$ and $300 \mathrm{~mm}$, and for coaches between $270 \mathrm{~mm}$ and $370 \mathrm{~mm}$.

The rig, consisting of an entrance and exit, was designed to provide different 'door' widths on each side: one side narrower to simulate an older-style bus, train or coach entrance, and the other side wider to simulate the access of newer buses and trains (see Figure 5). The grab handles on each side can be placed in two positions; on the narrow side they can be set at $100 \mathrm{~mm}$ or $200 \mathrm{~mm}$ from the entrance to the 'vehicle', on the wider side they can be set at $300 \mathrm{~mm}$ or $400 \mathrm{~mm}$ from the entrance. The step heights can be varied from $150 \mathrm{~mm}, 250 \mathrm{~mm}$ or $350 \mathrm{~mm}$ to reflect the worst-case scenario. There is a $100 \mathrm{~mm}$ horizontal gap between the ground and the 'vehicle' on both sides to reflect the horizontal gap between pavement/platform and the body of the vehicle.

The design of the rig raised a number of ethical considerations. In order to keep the trials as safe as possible, participants completed the transport abilities questionnaire before attempting to use the rig, thereby giving advance information of what would be likely to cause problems. The initial rig set-up was then adjusted according to these responses: able-bodied participants had both step heights set at the maximum $350 \mathrm{~mm}$, with handles set at $200 \mathrm{~mm}$ and $400 \mathrm{~mm}$ respectively. Less able participants had lower step heights and handle heights adjusted to their ability. When the rig was set correctly, participants were first asked to observe an experimenter demonstrating the task. Experimenters stood on both sides of the rig to offer assistance if required, and it was reinforced that participants should only attempt if they were happy to do so and they should take their time. When it came to stepping down participants were asked to first look at the required step and state whether they were happy to continue, before doing so in a controlled, safe manner. Anyone who felt unsure about the task was obviously free to stop, and steps could be removed if required during the trial.

\section{Use of whole body scanned data}

We are using a whole body scanner ([TC $]^{2} \mathrm{NX}_{12}$ Body Measurement System) to quickly collect body dimensions for use in constructing virtual human models of individual participants (see Figure 4). Participants undress in an enclosed private cubicle into lightweight and close-fitting clothing that is neutral to their skin tone, as high contrast with skin tone causes problems in attaining a complete scan. Once inside the scanner booth participants stand and then sit in standardised postures. The scan takes a matter of seconds, and then the person can exit and dress again. 
Traditional external anthropometric data were collected to enable comparison with measurements from the scanner to see if the scanner made the process quicker and more accurate for both able-bodied and less able participants. This comparison is on-going as the trials will not be completed until 2007. We have concerns that less able participants might experience problems getting into the required positions, and there are issues concerning those in wheelchairs, as the scanner dislikes reflection or high contrast.

\section{Emotional and cognitive dimensions}

The latest version of HADRIAN now includes data on an individual's ability to undertake a variety of transport-related tasks, such as vehicle ingress/egress, coping with uneven surfaces, steps, street furniture and complex pedestrian environments (see Figure 8). The latter includes capturing an individual's concerns about finding their way during an unfamiliar journey, changing transport modes (e.g. from a bus to a train), crossing busy roads, walking past large groups of people and/or graffiti and so on.

Our 'Transport Activities Questionnaire' has been developed to get rich and detailed information regarding participants' physical abilities, and also to tap into their cognitive and emotional issues surrounding transport usage. Participants are asked questions concerning: their physical abilities, based on the Office of Population Censuses and Surveys scale (Martin et al, 1988); any problems encountered when using trains, buses, trams, Londonstyle taxi cabs and minicab taxis; their ability to walk distances, as well as issues surrounding taking luggage on the different transport modes; the types and frequency of journeys made; problems in using stairs, lifts or escalators; and difficulties in understanding timetables and signs. The questionnaire also includes a request for information about problems experienced in the local area. Any local areas that participants identified as causing problems, when travelling, are visited by the experimenters to provide quantitative data to supplement the reports from the participants. For example, this may range from measuring the force required to open a heavy shop door, to assessing the cognitive and emotional issues at a transport node (e.g. changing from a bus to the train, involving crossing busy roads, walking through empty or crowded public spaces with poor street lighting). In short, the questionnaire aims to provide information concerning issues that may arise at any point during the whole journey process - from leaving home, travelling to a transport node; vehicle ingress/egress, changing transport modes and arriving at the destination.

\section{Testing and validation of the tool}

The tool provides a database of physical, emotional and cognitive information for 100 individuals, carefully selected to cover a very wide range of abilities. Whilst such data can be obtained traditionally from user trials, this can only be done for existing designs or those at the full-size prototype stage. The HADRIAN database will allow access to this rich data at a much earlier stage in the process, allowing planners, designers and operators of transport vehicles and systems to maximise social inclusion and access through the earliest consideration of the issues being faced by the users of public transport as they move to and fro between home, work, education, leisure and shopping. To validate the approach we plan to undertake some real world case studies within the testbed areas identified by the AUNTSUE consortium, or elsewhere if more suitable, where HADRIAN will be used by designers and planners to 'try out' different options for a specific design problem, be it a ticket barrier, a 
train station or access to the Olympics 2012. The tool should be able to identify the superior design option in terms of inclusivity, and to give direction as to how to improve it further, if appropriate. We also plan to compare the predictions made using HADRIAN for a specific virtual individual/object interaction with actual observations recorded during real world usage with the same individual.
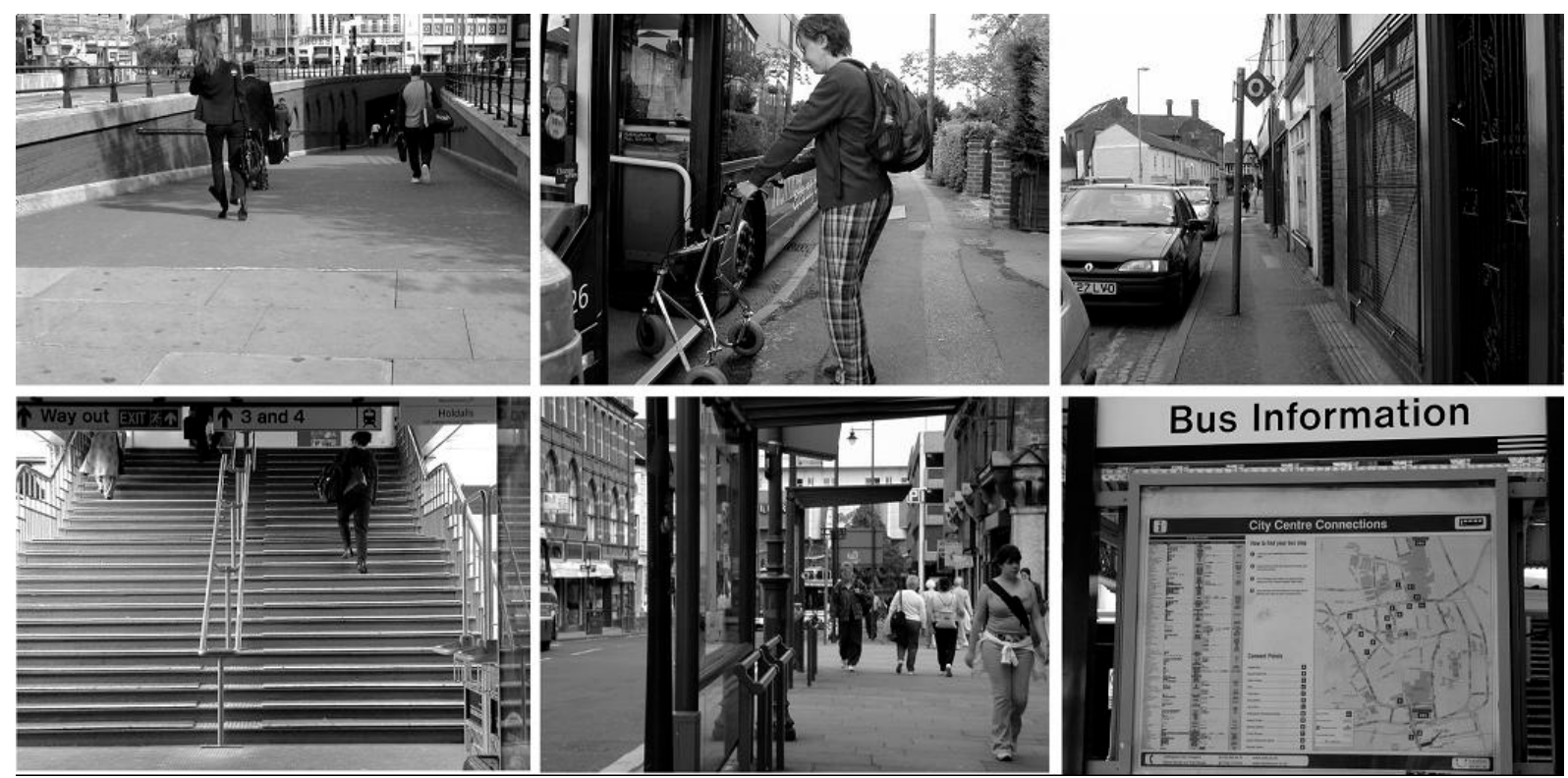

Figure 8: Examples of transport tasks and environments that have physical, cognitive and emotional dimensions for the traveller.

\section{Development of a personalized journey planner}

A specific feature of the enhanced HADRIAN tool will be a journey planner that compares an individual's physical, emotional and cognitive abilities with the demands that will placed upon that individual depending on the mode(s) of transport available and the route options. For example, some people do not use trains because of difficulties experienced getting on and off; some prefer not to walk through busy public areas or places with graffiti where they feel vulnerable; some experience problems finding their way on unfamiliar routes; some are unable to walk far or to climb steps with confidence; some are reluctant to cross busy road junctions; and so on. If a particular desired journey is unachievable or very difficult, either unaided or with support from others, then that person is likely to feel socially excluded. The prototype journey planner should allow people to predict problems that they may experience before deciding to make the journey. Hopefully, a suitable alternative route and choice of transport mode(s) can be identified using the planner such that the task demands fall within the person's abilities and preferences.

Whilst the database only comprises 100 individuals, it is envisaged that a web-based planner could be made available. Members of the public would need to complete an on-line questionnaire to provide relevant personal data on their body size (i.e. clothing sizes), general health, abilities and transport preferences. A major issue in such a planner would be compiling a database of the specific demands that would be placed on the traveller as a 
function of the exact geographic locations and the transport modes available for a particular journey. It is hoped that a pilot trial can be run in the testbed areas, with transport nodes, shopping areas, museums, theatres, cinemas and restaurants providing data for their surrounding areas (i.e. from the nearest bus stops, train station, taxi rank etc). The data could include, for example, distances by foot, details of steps/lifts/escalators, performance of street lighting/signposting, quality of the pavement/street surface, and perceived safety (e.g. ratings from a sample of people covering a range of ages and abilities) and objective safety (data on thefts, accidents, incidents etc). Figure 9 shows an initial screen interface for the journey planner.

Another issue for the envisaged personalized journey planner will be dealing with day-to-day transport problems that will influence the selection of optimum routes and modes of travel, such as cancelled or delayed trains, road works or equipment failure. Our vision for the future would be for the journey planner to receive up-to-date information from transport service providers, local communities and individual travellers via the internet. The modernday mobile phone is now equipped with high resolution cameras and access to the internet; combined with a global positioning system (GPS), this will allow travellers to take photos of transport problems they are personally experiencing and upload them with a text or voice explanation to a specialist web site. This would enable real-time information to be accessed by the journey planner. To close the loop, travellers already on a planned journey could be contacted via their mobile phones with a revised journey plan to deal with these unforeseen problems.

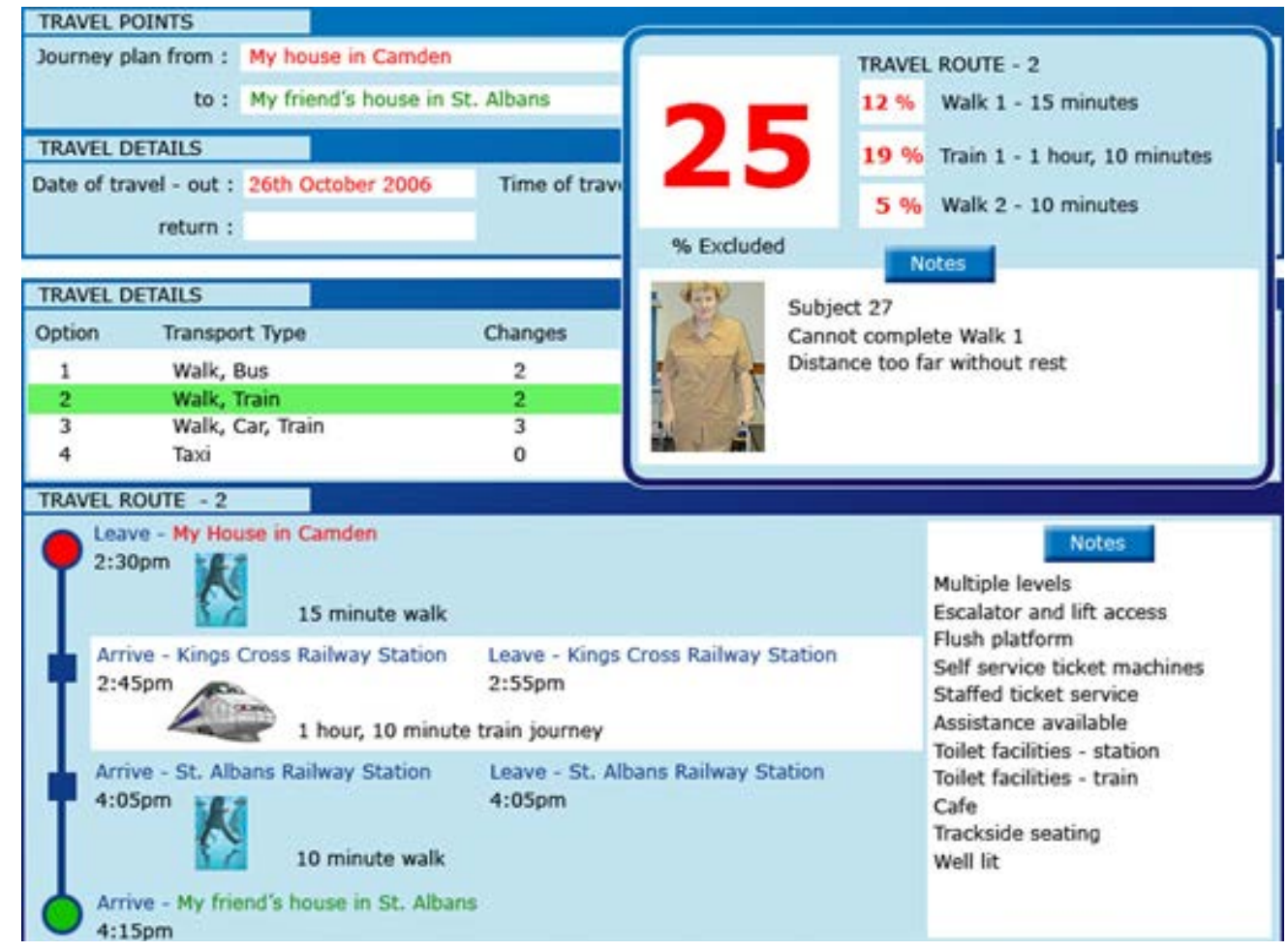

Figure 9: An initial screen interface for the prototype journey planner showing that $25 \%$ of the HADRIAN database would experience problems with Travel Option 2. A breakdown of problems for each stage of this journey is given, along with links to the individuals predicted to have problems. Such an analysis is useful for transport planners and designers.

Alternatively, the planner can be used to evaluate proposed journeys just for one person, i.e. as a personalised journey planner. 


\section{Concluding remarks}

It is hoped that inclusive design tools such as HADRIAN will lead the way in integrating inclusive design within contemporary design practice. To have the greatest impact upon the quality of peoples' lives, it is important that such an approach is adopted by the majority of design professionals. Currently, inclusive design is practiced by only a few specialist designers/ergonomists who have access to the relevant data and have knowledge of appropriate methods. Furthermore, current practice primarily addresses just the physical issues. The HADRIAN approach provides the relevant data on people of all shapes, sizes and abilities, plus the methodology to predict who will be 'designed out' or excluded from using a particular product or service whether this is due to physical, emotional or cognitive factors. We are not advocating that 'one design fits all', but the needs, abilities, preferences, concerns and aspirations of all people who would want to use the product or service should be considered at the concept stage of design. This may result in a single inclusive solution or in a range of products/services to cater for the various niche markets. 


\section{References}

Gyi, D.E., Sims, R.E., Porter, J.M., Marshall, R., and Case, K., 2004, Representing older and disabled people in virtual user trials: data collection methods. Applied Ergonomics, 35, 443-451.

Marshall, R., Porter, J.M., Sims, R., Gyi, D. and Case, K., 2005, HADRIAN meets AUNTSUE. Proceedings of INCLUDE 2005, Royal College of Art, London, UK (CD-ROM).

Martin, J., Meltzer, H. \& Elliot, D., 1988, OPCS surveys of disability in Great Britain: The prevalence of disability among adults, (Office of Population Censuses and Surveys, Social Survey Division, HMSO).

Martin, J., Meltzer, H. \& Elliot, D., 1988, OPCS surveys of disability in Great Britain: The prevalence of disability among adults, (Office of Population Censuses and Surveys, Social Survey Division, HMSO).

Porter, J.M., Case, K. and Freer, M.T., 1999, Computer aided design and human models. In: The Occupational Ergonomics Handbook, eds. Karwowski, W. and Marras, W., pp 479500, CRC Press LLC, Florida. ISBN 0-8493-2641-9.

Porter, J.M., Case, K., Marshall, R., Gyi, D.E. and Sims, R., 2004a, 'Beyond Jack \& Jill': Designing for individuals within populations using HADRIAN. International Journal of Industrial Ergonomics, vol 33, no 3, 249-264.

Porter, J.M., Marshall, R., Freer, M. and Case, K., 2004b, SAMMIE: A Computer Aided Ergonomics Design Tool. In: Working Postures \& Movements, tools for evaluation and engineering, eds N. Delleman, C. Haslegrave and D. Chaffin, pp 454-470, CRC Press LLC.

Porter, J.M., Marshall, R., Sims, R.E., Gyi, D.E. and Case, K., 2003, HADRIAN: a human modelling CAD tool to promote 'design for all'. Proceedings of INCLUDE 2003: inclusive design for society and business, CD-ROM, Volume 6, pp 222-228, March 2003, Royal College of Art, London, UK.

Public Service Vehicles Accessibility Regulations, 2000, Statutory Instrument No.1970, Department for Transport, UK.

Rail Vehicle Accessibility (Amendment) Regulations, 2000, Statutory Instrument No.3215, Department for Transport, UK.

Vanderheiden, G., Tobias, J. (2000). Universal design of consumer products: current industry practice and perceptions. Proceedings of the International Ergonomics Society/Human Factors and Ergonomics Society Congress 2000, 19-22. 